\title{
Neonatal near miss and the occurrence of negative outcomes in the first year of life: data from a national survey, Nascer no Brasil (Born in Brazil), 2011-2012
}

Pauline Lorena Kale 1

iD https://orcid.org/0000-0001-5439-9158

Sandra Costa Fonseca 2

Dhttps://orcid.org/0000-0001-5493-494X

Silvana Granado Nogueira Gama 3

https://orcid.org/0000-0002-9200-0387

${ }^{1}$ Departamento de Epidemiologia e Bioestatística. Instituto de Estudos em Saúde Coletiva. Universidade Federal do Rio de Janeiro. Av. Horácio Macedo, s.n. Ilha do Fundão. Cidade Universitária. Rio de Janeiro, RJ, Brasil. CEP: 21.941-598. E-mail: pkale@iesc.ufrj.br

2 Departamento de Epidemiologia e Bioestatística. Instituto de Saúde Coletiva. Universidade Federal Fluminense. Niterói, RJ, Brasil.

3 Departamento de Epidemiologia e Métodos Quantitativos em Saúde. Escola Nacional de Saúde Pública Sérgio Arouca. Fundação Oswaldo Cruz. Rio de Janeiro, RJ, Brasil.

\begin{abstract}
Objectives: estimate the strength of association between neonatal near miss and the negative outcomes in the child's first year of life.

Methods: a prospective cohort study on neonatal survivors originating from a national survey "Nascer no Brasil (Born in Brazil), 2011-2012." Main exposure: neonatal near miss (NNM). Negative outcomes: breastfeeding, hospitalization, and post neonatal death (telephone interview). For each outcome, the odds ratio (OR) were estimated by univariate $(p<0.2)$ and multivariate $(p<0.05)$ logistic regression models.

Results: among 15,675 children 3.3\% were neonatal near miss. Neonatal near miss was associated, after adjusting, to: weaning $(O R=1.8)$; hospitalization after hospital discharge $(O R=2.2)$; remained hospitalized $(O R=65.6)$ and post neonatal death $(O R=52.4)$ The increased $O R$ after adjusting revealed negative confounding, such as "remained hospitalized since childbirth" $\left(O R_{\text {crude }}=21.1\right.$ and $\left.O R_{\text {adjusted }}=65.6\right)$.

Conclusions: although neonatal near miss reflects a good quality of health care, avoiding neonatal death, these survivors have higher risk of negative outcomes in the first year of life. Key words Near miss, Infant mortality, Hospitalization, Breastfeeding
\end{abstract}

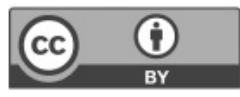




\section{Introduction}

Children born with life-threatening conditions have a higher risk of death, especially during the neonatal period. Even surviving this critical period after birth, which is defined as neonatal near miss, these children remain with the worse prognosis, such as childhood mortality ${ }^{1}$ and possibly other negative outcomes, not yet have been reported in scientific publications, as cases have occurred in maternal near miss. ${ }^{2}$

There is no universal definition of neonatal near miss. The definition is based on the presence of at least one clinical, laboratorial, management or pragmatic criteria. Isolated criteria associated with neonatal near miss include gestational age below 32 weeks (very preterm), 3 birth weight below $1,500 \mathrm{~g}$ (very low birth weight), ${ }^{3}$ use of mechanical ventilation, and organ-system dysfunctions or failure. These events have been extensively studied as independent risk factors for this age group.

Very preterm birth is associated with no breastfeeding, $, 4,5$ hospitalization, 6,7 and post neonatal death, 7 among other negative outcomes during childhood. Very low birth weight is also known to have an association with a higher frequency of rehospitalization and post neonatal mortality. 8,9 The necessity of a mechanical ventilation is a predictor on neonatal mortality. ${ }^{10}$ However, it is realistic that the same occurs with neonatal near miss cases.

In Brazil, hospital-based11-15 and populationbased ${ }^{1}$ studies estimate the burden of neonatal near miss. In 2011-2012, the national rate of neonatal near miss was 39.2 per thousand live births. 14 Even considering different definitions of neonatal near miss and the representativeness of the studies, the relation between the frequency of neonatal near miss cases and neonatal deaths remains at about $3: 11,15$ and 4:1.11,14 That is, 3 to 4 neonatal near miss cases occur for each neonatal death, thus dimensioning the contingent of the most vulnerable surviving children and their respective families that will demand more State support.

This study aimed to estimate the strength of the association between neonatal near miss and breastfeeding, hospitalization, and post neonatal death, in a cohort of neonatal survivors' first year of life in 2011-2012.

\section{Methods}

This is a prospective cohort study on neonatal survivors based on the information from the national hospital-based survey "Nascer no Brasil" (Born in
Brazil) conducted between February 2011 and October 2012.16 In this survey, live births were monitored to verify the occurrence of neonatal death during fieldwork, and subsequently, comparing database information from the Sistema de Informações sobre Mortalidade (SIM) (Mortality Information System). Mothers were contacted by telephone for interview in the post neonatal period to obtain maternal and infant information. Single gestation neonatal survivors $(n=23,378)$ were eligible for this cohort study. About $32 \%$ of data loss occurred because researchers were unable to reach the mothers, due to they have moved or the absence of their contact information. Of 15,680 telephone interviews, five children were excluded from the analyses due to inconsistences between the date of the interview and their date of birth (study population=15,675).

The main exposure of the study were the survivors in the neonatal period classified as neonatal near miss cases (yes/no) (these data were obtained from medical records and SIM databases). The definition of neonatal near miss, validated as survey data, is the presence of one of the following criteria: birthweight $<1500 \mathrm{~g}$; gestational age $<32$ weeks; Apgar score in the fifth minute $<7$, referred to pragmatic criteria, besides mechanical ventilation and the presence of congenital anomalies, they survived the first 27 days of life. 14

The telephone interviews were conducted in the post neonatal period. For mothers, whose child had died or continued to be hospitalized since birth, the questions about breastfeeding and hospitalization after hospital discharge were not asked during the interview. For breastfeeding outcomes, we included data on children who lived with their mothers, and in cases where the child lived with someone else, the mother was contacted to answer questions about her child.

Negatives infant outcomes were obtained by telephone interview. These included: not have breastfed since the previous day (from yesterday to today, the day of the interview); remained hospitalized since childbirth; had been hospitalized at some point after maternity discharge (exclude the previous situation); and death of a child in the post neonatal period (28 to 364 days after birth).

We obtained data regarding potential confounders, such as geographical and maternal characteristics, and at the time of childbirth by interviewing the parturient woman, medical records and cards were obtained. Geographical variables included: geographical macro-region (North/ Northeast/Southeast/South/Midwest) and the loca- 
tion of the birth hospital (capital/countryside). Maternal variables included: age $(<20 / 20-34 / \geq 35$ years); skin color (white/mixed/black); schooling (incomplete elementary school/complete elementary school/incomplete high school and complete high school/higher education or more); economic status based on the Brazilian Association of Research Companies' (ABEP) classification (levels A, B, C, D or $E$ based on level of education of the head of the family and family asset - http://www.abep.org/ criterio-brasil); marital status (with/without a partner); paid work activity (yes/no); primiparity (yes/no); smoking before/during pregnancy (yes/no) and alcohol consumption during pregnancy (yes/no), according to Tolerance Worry Eye-opener AmnesiaCutdown (TWEAK), 17 whose adapted categories are: no consumption/non-abusive alcohol consumption/abusive alcohol consumption. The exclusion of yellow and indigenous skin color was due to the small percentage of participants in these categories ( $1.1 \%$ and $0.3 \%$, respectively). All variables were measured in the hospital survey. The frequency of these variables and the neonatal near miss were compared between the loss to follow-up and the study population.

The homogeneity between the loss due to not conducting a telephone interview and the population study were assessed by using Pearson's chi-square test, considering the statistical significance level of $p<0,05$.

For each outcome univariate (level of statistical significance $<0.2$ ) and multivariate (level of statistical significance $<0.5$ ) analysis were performed by using logistic regression models. The variables selected in the univariate models were incorporated into the multivariate model, according to the geographical and maternal characteristics: starting with geographic variables (model 1) and later, maternal variables (model 2 ).

"Nascer no Brasil" (Born in Brazil) survey used a complex sample, considering all stages in its statistical analysis with calibration and weighting. The results presented estimates for the studied population $(2,337,476$ childbirths), based on the sample of 23,894 interviewed puerperal women. ${ }^{18}$ Analysis of complex samples were used, aiming to incorporate the effect of the study design, and weighting data according to the sampling plan and design effect. The analysis were performed by using the IMB SPSS for Windows, v. 19.0 program.

This study was approved by the Research Ethics Committee of the Escola Nacional de Saúde Pública Sérgio Arouca, Fundação Oswaldo Cruz (ENSP/Fiocruz), under the document number
$92 / 2010$. All precautions were taken to ensure the confidentiality of the information gathered. Before each interview, we obtained a digital consent from each puerperal women who read and signed the informed consent form.

\section{Results}

Loss to not performing telephone interviews and the population study were only homogeneous in relation to the frequency of neonatal near miss cases (Table 1). For other characteristics analyzed, the differences demonstrated a greater vulnerability of loss $(p<0.05)$ : the highest frequency of loss were in the North and Northeast regions; in the countryside; public payment source; maternal age less than 35 years old; mixed and black colored skin; low schooling level; non-paid work; low socioeconomic status; without a partner; multiparous and maternal smokers (Table 1).

Of 15,675 children whose information was gathered by their mothers via telephone interview, there were 40 post neonatal deaths, 49 children remained hospitalized since childbirth, and 705 children who were rehospitalized after maternity discharge, of which 11 remained hospitalized at the time of the interview. The proportion of neonatal near miss cases in the population study was $3.3 \%$. The results of the univariate analysis for each outcome are presented in Table 2.

Neonatal near miss was strongly associated with all the outcomes $(p<0.001)$. Statistical univariate analysis revealed geographical characteristics, excluding hospital location concerning hospitalization after hospital discharge were associated with the outcomes $(p<0.2)$, although the directions were distinct from each other. All the regions when compared to the South region presented a protective effect on no breastfeeding and hospitalization after maternity discharge, and a risk effect on remained hospitalized since childbirth. The location of the countryside hospital represented a risk factor for no breastfeeding and a protective factor on remained hospitalized since childbirth and post neonatal death. All the maternal characteristics, except for alcohol consumption during pregnancy, were associated with no breastfeeding, skin color and alcohol consumption during pregnancy were associated with hospitalization after maternity discharge. Paid work and maternal smoking were associated with remained hospitalized since childbirth, while primiparity was associated to the post neonatal outcome.

In multivariate analysis, neonatal near miss remained as a strong risk factor for all the investi- 
Comparison among the interviewees (population study) and the non-interviewees (losses) by phone interviews, Nascer no Brasil (Born in Brazil) survey, 2011-2012.

\begin{tabular}{|c|c|c|c|}
\hline Variables & n (unweighted)* & $\begin{array}{l}\% \text { losses on follow-up } \\
\text { (weighted) }\end{array}$ & $p^{* *}$ \\
\hline \multicolumn{4}{|l|}{ Main Exposure } \\
\hline Near Miss & & & 0.586 \\
\hline yes & 762 & 31.4 & \\
\hline no & 22,392 & 32.3 & \\
\hline \multicolumn{4}{|l|}{ Geographic } \\
\hline Region & & & $<0.001$ \\
\hline North & 2,805 & 47.2 & \\
\hline Northeast & 5,935 & 45.6 & \\
\hline Southeast & 7,861 & 26.7 & \\
\hline South & 4,055 & 15.7 & \\
\hline Midwest & 2,722 & 29.9 & \\
\hline Hospital location & & & $<0.001$ \\
\hline capital & 7,370 & 27.4 & \\
\hline countryside & 16,008 & 34.7 & \\
\hline \multicolumn{4}{|l|}{ Maternal } \\
\hline Age group (years) & & & $<0.001$ \\
\hline$<20$ & 4,240 & 39.5 & \\
\hline $20-34$ & 16,552 & 31.0 & \\
\hline$\geq 35$ & 2,582 & 29.6 & \\
\hline \multicolumn{4}{|l|}{ Skin color } \\
\hline white & 8,407 & 25.6 & $<0.001$ \\
\hline black & 1,816 & 37.5 & \\
\hline mixed & 12,798 & 36.1 & \\
\hline \multicolumn{4}{|l|}{ Paid work } \\
\hline yes & 9,934 & 25.3 & $<0.001$ \\
\hline no & 13,441 & 37.7 & \\
\hline \multicolumn{4}{|l|}{ Schooling } \\
\hline incomplete elementary school & 5,814 & 48.6 & $<0.001$ \\
\hline complete elementary school & 5,607 & 32.2 & \\
\hline high school & 9,141 & 24.9 & \\
\hline higher education or more & 2,712 & 22.7 & \\
\hline Economic status & & & $<0.001$ \\
\hline Upper class $(A+B)$ & 6,540 & 21.7 & \\
\hline Middle class (C) & 11,391 & 28.6 & \\
\hline Lower class $(D+E)$ & 5,229 & 53.4 & \\
\hline Marital Status & & & 0.009 \\
\hline With a partner & 4,000 & 34.2 & \\
\hline Without a partner & 19,365 & 32.0 & \\
\hline Primiparity & & & $<0.001$ \\
\hline yes & 10,930 & 29.8 & \\
\hline no & 12,447 & 34.8 & \\
\hline Smoking & & & 0.007 \\
\hline yes & 3,688 & 34.3 & \\
\hline no & 19,676 & 32.1 & \\
\hline Consumption of alcohol & & & $<0.001$ \\
\hline no & 19,872 & 32.9 & \\
\hline non-abusive alcohol consume & 852 & 24.4 & \\
\hline abusive alcohol consume & 2,108 & 30.6 & \\
\hline
\end{tabular}

Note: Only livebirths of single birth were selected; * Not all the totals are equal due to the ignored information; **Pearson's chi-square test. 
Table 2

\begin{tabular}{|c|c|c|c|c|c|c|c|c|c|c|c|c|}
\hline \multirow[t]{2}{*}{ Variables } & \multicolumn{3}{|c|}{$\begin{array}{l}\text { Did not breastfeed } \\
\text { yesterday/today }\end{array}$} & \multicolumn{3}{|c|}{$\begin{array}{l}\text { Hospitalization after } \\
\text { discharge of childbirth }\end{array}$} & \multicolumn{3}{|c|}{ Remain hospitalized } & \multicolumn{3}{|c|}{ Post neonatal death } \\
\hline & OR & $\mathrm{Cl} 95 \%$ & $p$ & OR & $\mathrm{Cl} 95 \%$ & $p$ & OR & $\mathrm{Cl} 95 \%$ & $p$ & OR & $\mathrm{Cl} 95 \%$ & $p$ \\
\hline \multicolumn{13}{|l|}{ Main Exposure } \\
\hline Near Miss & & & $<0.001$ & & & 0.131 & & & $<0.001$ & & & $<0.001$ \\
\hline yes & 1.67 & $1.31-2.14$ & & 2.14 & $1.45-3.14$ & & 21.133 & $6.82-65.5$ & & 51.41 & $22.45-117.7$ & \\
\hline no & 1 & & & 1 & & & 1 & & & 1 & & \\
\hline \multicolumn{13}{|l|}{ Geographic } \\
\hline Region & & & $<0.001$ & & & 0.006 & & & 0.044 & & & 0.055 \\
\hline North & 0.34 & $0.24-0.48$ & & 0.67 & $0.47-0.95$ & & 9.30 & $1.96-44.0$ & & 0.34 & $0.04-2.64$ & \\
\hline Northeast & 0.85 & $0.65-1.11$ & & 0.65 & $0.48-0.89$ & & 8.05 & $1.30-49.9$ & & 1.25 & $0.41-3.77$ & \\
\hline Southeast & 0.78 & $0.64-0.95$ & & 0.63 & $0.49-0 ; 81$ & & 7.33 & $1.81-29.6$ & & 0.35 & $0.11-1.08$ & \\
\hline South & 1 & & & 1 & & & 1 & & & 1 & & \\
\hline Midwest & 0.55 & $0.43-0.71$ & & 0.74 & $0.49-1.10$ & & 4.76 & $0.96-23.5$ & & & & \\
\hline Hospital location & & & 0.161 & & & 0.906 & & & 0.172 & & & 0.187 \\
\hline capital & 1 & & & 1 & & & 1 & & & 1 & & \\
\hline countryside & 1.15 & $0.95-1.39$ & & 1.01 & $0.83-1.24$ & & 0.46 & $0.15-1.41$ & & 0.55 & $0.23-1.33$ & \\
\hline \multicolumn{13}{|l|}{ Maternal } \\
\hline Age group (years) & & & 0.057 & & & 0.667 & & & 0.853 & & & 0.446 \\
\hline$<20$ & 0.90 & $0.76-1.07$ & & 1.11 & $0.88-1.40$ & & 1.07 & $0.36-3.19$ & & 1.65 & $0.64-4.23$ & \\
\hline 20-34 & 1 & & & 1 & & & 1 & & & 1 & & \\
\hline$\geq 35$ & 1.25 & $0.97-1.62$ & & 0.98 & $0.72-1.34$ & & 0.75 & $0.21-2.60$ & & 0.64 & $0.14-2.95$ & \\
\hline Skin color & & & $<0.001$ & & & 0.028 & & & 0.697 & & & 0.405 \\
\hline white & 1 & & & 1 & & & 1 & & & 1 & & \\
\hline black & 0.88 & $0.60-1.30$ & & 0.83 & $0.61-1.14$ & & 1.06 & $0.14-8.05$ & & 0.90 & $0.20-4.05$ & \\
\hline mixed & 0.75 & $0.65-0.86$ & & 0.77 & $0.63-0.93$ & & 1.49 & $0.58-3.81$ & & 0.57 & $0.25-1.32$ & \\
\hline Paid work & & & 0.006 & & & 0.648 & & & 0.154 & & & 0.702 \\
\hline yes & 1 & & & 0.95 & $0.78-1.17$ & & 1.93 & $0.78-4.78$ & & 1.18 & $0.50-2.80$ & \\
\hline no & 0.85 & $0.76-0.95$ & & 1 & & & 1 & & & 1 & & \\
\hline Schooling & & & 0.173 & & & 0.280 & & & 0.192 & & & 0.623 \\
\hline incomplete elementary school & 0.92 & $0.67-1.16$ & & 0.98 & $0.69-1.40$ & & 1.31 & $0.39-4.39$ & & 0.96 & $0.23-4.10$ & \\
\hline complete elementary school & 0.76 & $0.56-1.04$ & & 1.18 & $0.87-1.62$ & & 2.79 & $0.73-10.7$ & & 0.47 & $0.12-1.86$ & \\
\hline high school & 0.88 & $0.67-1.16$ & & 0.94 & $0.68-1.28$ & & 0.81 & $0.24-2.70$ & & 0.85 & $0.25-2.80$ & \\
\hline higher education or more & 1 & & & 1 & & & 1 & & & 1 & & \\
\hline
\end{tabular}


Table 2

concluded

Univariate analysis on geographic and maternal characteristics according to negative infant outcome, Brazil, 2011-2012.

\begin{tabular}{|c|c|c|c|c|c|c|c|c|c|c|c|c|}
\hline \multirow[t]{2}{*}{ Variables } & \multicolumn{3}{|c|}{$\begin{array}{l}\text { Did not breastfeed } \\
\text { yesterday/today }\end{array}$} & \multicolumn{3}{|c|}{$\begin{array}{l}\text { Hospitalization after } \\
\text { discharge of childbirth }\end{array}$} & \multicolumn{3}{|c|}{ Remain hospitalized } & \multicolumn{3}{|c|}{ Post neonatal death } \\
\hline & OR & $\mathrm{Cl} 95 \%$ & $p$ & OR & $\mathrm{Cl} 95 \%$ & $p$ & OR & $\mathrm{Cl} 95 \%$ & $p$ & OR & $\mathrm{Cl} 95 \%$ & $p$ \\
\hline Economic status & & & 0.007 & & & 0.729 & & & 0.062 & & & 0.383 \\
\hline Upper class $(A+B)$ & 1 & & & 1 & & & 1 & & & 1 & & \\
\hline Middle class (C) & 0.76 & $0.62-0.93$ & & 1.09 & $0.88-1.35$ & & 2.55 & $0.92-7.06$ & & 0.69 & $0.28-1.72$ & \\
\hline Lower class $(D+E)$ & 0.71 & $0.56-0.90$ & & 1.05 & $0.80-1.39$ & & 0.71 & $0.25-2.01$ & & 1.44 & $0.48-4.30$ & \\
\hline Marital status & & & $<0.001$ & & & 0.822 & & & 0.921 & & & 0.298 \\
\hline With a partner & 1.17 & $0.98-1.41$ & & 0.97 & $0.75-1.25$ & & 1.05 & $0.41-2.72$ & & 0.57 & $0.20-1.65$ & \\
\hline Without a partner & 1 & & & 1 & & & 1 & & & 1 & & \\
\hline Primiparity & & & 0.007 & & & 0.219 & & & 0.479 & & & 0.087 \\
\hline yes & 1 & & & 1 & & & 1 & & & 1 & & \\
\hline no & 0.80 & $0.69-0.94$ & & 1.13 & $0.93-1.38$ & & 1.41 & $0.54-3.67$ & & 0.49 & $0.22-1.11$ & \\
\hline Smoking & & & 0.028 & & & 0.991 & & & 0.179 & & & 0.746 \\
\hline yes & 1.20 & $1.02-1.41$ & & 1.00 & $0.79-1.27$ & & 2.74 & $0.63-11.9$ & & 0.85 & $0.32-2.26$ & \\
\hline no & 1 & & & 1 & & & 1 & & & 1 & & \\
\hline Consumption of alcohol & & & 0.802 & & & 0.108 & & & 0.221 & & & $<0.001$ \\
\hline no & 1 & & & 1 & & & 1 & & & 1 & & \\
\hline non-suspected of heavy & 1.04 & $0.74-1.48$ & & 1.10 & $0.72-1.68$ & & 0.69 & $0.09-5.25$ & & 0.00 & $0.00-0.00$ & \\
\hline Suspected of heavy consume & 1.09 & $0.85-1.39$ & & 0.73 & $0.52-1.01$ & & 3.97 & $0.80-19.69$ & & 1.34 & $0.37-4.93$ & \\
\hline
\end{tabular}


Odds ratio for the adjusted outcome on geographic and maternal variables according to the main exposure (neonatal near miss), Brazil, 2011-2012.

\begin{tabular}{|c|c|c|c|}
\hline Outcomes / Models & OR & $\mathrm{Cl} 95 \%$ & $p$ \\
\hline \multicolumn{4}{|c|}{ 1.No breastfeeding yesterday until today } \\
\hline Model 1.1 & 1.7 & $1.3-2.2$ & $<0.001$ \\
\hline Model 1.2 & 1.8 & $1.4-2.3$ & $<0.001$ \\
\hline \multicolumn{4}{|c|}{ 2. Hospitalization after discharge of childbirth } \\
\hline Model 2.1 & 2.2 & $1.5-3.2$ & $<0.001$ \\
\hline Model 2.2 & 2.2 & $1.5-3.3$ & $<0.001$ \\
\hline \multicolumn{4}{|c|}{ 3. Remained hospitalized since childbirth } \\
\hline Model 3.1 & 64.5 & $23.5-177.4$ & $<0.001$ \\
\hline Model 3.2 & 65.6 & $24.1-178.5$ & $<0.001$ \\
\hline \multicolumn{4}{|c|}{ 4. Post neonatal death } \\
\hline Model 4.1 & 51.4 & $22.5-117.2$ & $<0.001$ \\
\hline Model 4.2 & 52.4 & $22.8-120.3$ & $<0.001$ \\
\hline
\end{tabular}

Model 1.1: geographic variables (Region and Hospital location).

Model 1.2: Model 1.1 + maternal variables (age group, skin color, schooling, economic status, paid work, marital status, primiparity, smoking and consumption of alcohol).

Model 2.1: geographic variables (Region)

Model 2.2: Model2.1 + maternal variables (skin color and consumption of alcohol).

Model 3.1: geographic variables (Region and Hospital location).

Model 3.2: Model 3.1 + maternal variables (schooling, paid work, economic status, smoking).

Model 4.1: geographic variables (Region and Hospital location).

Model 4.2: Model 4.1 + maternal variables (primiparity and consumption of alcohol).

gated outcomes (Table 3). Considering the most severe outcome and the lower frequency in the population study - remained hospitalized since childbirth and post neonatal death - the odds ratios were 65.6 and 52.4, respectively, with broad confidence intervals of $95 \%$. The increase of the odds ratio referred to neonatal near miss univariate to multivariate analysis indicate the presence of negative confounding $\left(\mathrm{OR}_{\text {crude }}<\mathrm{OR}_{\text {adjusted }}\right)$. This change was substantial only when considering the outcome was who remained hospitalized since childbirth $\left(\mathrm{OR}_{\text {crude }}=21.1\right.$ and $\left.\mathrm{OR}_{\text {adjusted }}=65.6\right)$.

\section{Discussion}

The hypothesis of a worse prognosis for neonatal near miss cases was confirmed and the estimated odds ratios on the outcomes for no breastfeeding $(\mathrm{OR}=1.8)$, hospitalization after maternity discharge $(\mathrm{OR}=2.2)$, remained at the hospital after childbirth $(\mathrm{OR}=65.6)$ and post neonatal death $(\mathrm{OR}=52.4)$ in the first year of life were strongly associated.

We found only a similar study, a population- based birth cohort, that presented an estimate of a burden on negative outcomes among neonatal near miss cases. There was a $4.6 \%$ reduction in the survival of neonatal near miss cases (based only on pragmatic criteria) up to five incomplete years of life in the city of Rio de Janeiro. ${ }^{1}$ Even in studies on isolated pragmatic criteria, post neonatal outcomes have been little explored. ${ }^{7}$

The importance of maternal breastfeeding for the child's health extends to the second semester of his/her life. ${ }^{19}$ However, near miss cases had a higher frequency on no breastfeeding since the day before the interview. A Brazilian study has already shown that gestational age less than 32 weeks decreases breastfeeding duration in the child's first year of life. ${ }^{4}$ Unsuccessful maternal breastfeeding between neonatal near miss can also, in part, be explained by the presence of congenital anomaly (28\% among near miss cases - data not presented), as some of them interfere with the child's suction, such as the cleft palate and cleft lip. 20

Hospitalization and post neonatal death can be, in fact, consequences of severe conditions at birth. 
Among children born less than 39 weeks of gestation, gestational age has an inverse relation with the rates of hospitalization and infant mortality. ${ }^{7}$ Birth defects are also frequent in the first year of life, accounting for $35 \%$ of the total hospitalization cost at this age group in the USA in 2013.21

Congenital heart disease is one of the most frequent malformations. ${ }^{22}$ After a cardiac procedure, children often require readmission in the first year of life for both further planned procedures and for unplanned reasons, and they are at high risk of mortality. 23

In an increasing severity gradient of analyzed outcomes, the hospitalization length since childbirth and post neonatal death presented very high adjusted odds ratios. Despite strong associations to absolute frequency of events are rare, which may partly explain the width of the respective confidence intervals.

Only for the hospitalization length, we detected that geographical and maternal characteristics were negative confounders of the association with neonatal near miss. The geographical regions with the highest socioeconomic development level are in the South and Southeast, and they offer more complex and high-tech health services, especially those located in capitals and hospitals located in these areas tend to have a higher frequency of neonatal near miss cases. 11,14 Among maternal characteristics confounders, social class, paid work, and schooling represent directly or indirectly on the socioeconomic situation. Maternal smoking, as a confounder, is associated with prematurity, low birth weight and cleft lip, 24,25 characteristics that may be present in the classification of neonatal near miss cases and these are also related to a longer hospitalization. Additionally, smoking itself leads to a higher frequency of neonatal hospitalization, 26 and a higher incidence of pulmonary bronchodysplasia which increases hospitalization length. 27

As the main exposure, our definition of neonatal near miss in this study was validated with the research data (sensitivity: $92.5 \%$ and specificity: $97.1 \%$ ). It is based on the five criteria proposed by Silva et al.4: three pragmatic criteria (very preterm, very low birth weight and Apgar score in the fifth minute less than seven), one management criterion (mechanical ventilation), and one clinical (congenital anomaly). In a systematic review on neonatal near miss definitions, only four articles were selected, and the use of higher cut-off points for pragmatic criteria is recommended: birth weight $(<1750 \mathrm{~g})$ and gestational age $(<33$ weeks).28 We tested these cutoff points by adapting the original near miss definition by Silva et al. 14 and found equally strong and positive associations with the studied outcomes (data not presented). As for congenital anomalies, we agreed with the authors' discussion that many congenital anomalies that lead to death are not preventable. ${ }^{14}$ Additionally, we added that the largest contingent of congenital anomalies is mild in severity, not implying a greater risk of death. Despite criticisms arose, the definition on neonatal near miss used in our study was able to identify an association with negative outcomes in the child's first year of life.

The main strength of our study was to estimate the burden of negative outcomes among neonatal near miss cases in the first year of life. We also highlight the size and national representativeness of the sample.

Among the limitations, selective losses may have occurred, although the frequency of the main exposure was not different from the population study. The very own definition of loss in this study was the absence or change of the telephone number, which is relatively common in poorer populations, living in the outskirts, and this explains, at least in part, the greater vulnerability found. The absence in the literature of other potential confounders, or alongside unavailable data to include in the analysis may have affected the results. Self-reported maternal information, such as maternal smoking, may be underestimated due to pregnant women's knowledge of harmful effects to mother and child's health. 29 The fact that the condition of an ex-smoker was not considered as a distinct category of maternal smoking, it may have weakened the magnitude of the associations. In addition to self-report on alcohol consumption was measured using TWEAK. Each screening test for alcoholism has advantages and limitations concerning psychometric properties, which may result in information bias. ${ }^{30}$

We conclude that although neonatal near miss reflects on good health care avoiding neonatal death, there is a worse prognosis for these survivors.

Therefore, it is imperative to invest in prenatal care to reduce births with life-threatening conditions. When these conditions are inevitable, these children must be cared for by specialists. In the city of Rio de Janeiro, it was estimated that preventing life-threatening conditions at birth could reduce up to $97.6 \%$ of preventable deaths in children under five years of age. ${ }^{1}$ The reduction in deaths and other negative outcomes, such as hospitalization and weaning have a desirable and attainable impact on child health. 


\section{Authors' contribution}

Kale PL, Gama SGN and Fonseca SC participated in the conception and initial writing of the manuscript. All the authors participated of the analysis of data and interpretation of the results and in the review and final approval of the manuscript.

\section{References}

1. Kale PL, Silva KS, Saraceni V, Coeli CM, Torres TZG, Vieira FMSB, Rocha NM, Fonseca SC et al. Life-threatening conditions at birth: an analysis of causes of death and survival estimate for under-five children in live birth cohorts. Cad Saúde Pública. 2019; 35(7): e00186418.

2. StorengKT, Drabo S, GanabaR, SundbyJ, CalvertC, FilippiV. Mortality after near-miss obstetric complications in Burkina Faso: medical, social and health-care factors. Bull World Health Organ. 2012; 90:418-25.

3. American Academy of Pediatrics (AAP)\& The American College of Obstetricians and Gynecologists (ACOG). Guidelines for Perinatal Care. Eighth edition. Elk Grove Village, IL: AAP; Washington, DC: ACOG;2017.

4. Freitas BAC, Lima LM, Carlos CFLV, Priore SE, Franceschini SCC. Duração do aleitamento materno em prematuros acompanhados em serviço de referência secundário. Rev PaulPediatr. 2016; 34(2): 189-96.

5. Rodrigues C, Teixeira R, Fonseca MJ, Zeitlin J, Barros H Portuguese EPICE (Effective Perinatal IntensiveCare in Europe) Network. Prevalence and duration of breastmilk feeding invery preterm infants: A 3-year follow-up study and a systematic literature review. Paediatr Perinat Epidemiol.2018; 32 (3): 237-46.

6. Klitkou ST, Iversen T, Stensvold HJ, Rønnestad A. Use of hospital-based health care services among children aged 1 through 9 years who were born very preterm- a populationbased study. BMC Health Serv Res. 2017; 17 (1): 571.

7. Iacobelli S, Combier E, Roussot A, Cottenet J, Gouyon JB, Quantin C. Gestational age and 1-year hospital admission or mortality: a nation-wide population-based study. BMC Pediatr. 2017; 17 (1): 28

8. Tchamo ME, Prista A, Leandro CG. Lowbirth weight,very lowbirth weight and extremely low birth weight in African children aged between 0 and 5 years old: a systematic review. J Dev Orig Health Dis. 2016; 7 (4): 408-15.

9. Kuint J, Lerner-Geva L, Chodick G, Boyko V, Shalev V, Reichman B; Israel Neonatal Network. Type of ReHospitalization and Association with Neonatal Morbidities inInfants of Very Low Birth Weight. Neonatol. 2019; 115 (4): 292-300.

10. Fischer HS, Schmölzer GM, Cheung PY, Bührer C. Sustained inflations and avoiding mechanical ventilation to prevent death or bronchopulmonary dysplasia: a metaanalysis. Eur Respir Rev. 2018; 27 (150). pii: 180083.

11. Brasil DRPA, Vilela MBR, França KEX, Sarinho SW. Neonatal morbidity near miss in tertiary hospitals in a capital of Northeast Brazil. Rev Paul Pediatr. 2019; 37 (3): 275-82.
12. França KEX, Vilela MBR, Frias PG, Gaspar GS, Sarinho SW. Near miss neonatal precoce identificado com base em sistemas de informação em saúde. Cad Saúde Pública. 2018; 34 (9): e00167717.

13. Kale PL, Mello-Jorge MHP, Silva KS, Fonseca SC Neonatal near miss and mortality: factors associated with life-threatening conditions in newborns at six public maternity hospitals in Southeast Brazil. Cad Saúde Pública. 2017; 33 (4): e00179115.

14. Silva AAM, Leite AJM, Lamy ZC, Moreira MEL, Gurgel RQ, Cunha AJLA, Leal MC. Morbidade neonatal near miss na pesquisa Nascer no Brasil. Cad Saúde Pública.2014;30 (Supl. 1): S182-91.

15. Pileggi C, Souza JP, Cecatti JG, Faúndes A. Neonatal near miss approach in the 2005 WHO Global Survey Brazil. J Pediatr (Rio J).2010; 86 (1): 21-6.

16. Leal MC, da Silva AA, Dias MA, da Gama SG, Rattner D, Moreira ME, Theme Filha MM, Domingues RMSM, Pereira APE, Torres JA, Bittencourt DAS, D'Orsi E, Cunha AJ, Leite AJM, Cavalcante RS, Lansky S, Diniz CSG, Szwarcwald CL. Birth in Brazil: national survey into labour and birth. Reprod Health. 2012; 9:15.

17. Moraes CL, Reichenheim ME. Screening for alcohol use by pregnant women of public health care in Rio de Janeiro, Brazil. Rev Saúde Pública. 2007; 41:695-703.

18. Vasconcellos MT, Silva PL, Pereira AP, Schilithz AO, Souza Junior PR, Szwarcwald CL. Sampling design for the Birth in Brazil: National Survey into Labor and Birth. Cad Saúde Pública. 2014; 30 (Suppl. 1): S1-10.

19. OMS (Organização Mundial de Saúde). Evidências científicas dos dez passos para o sucesso do aleitamento materno. Brasília, DF: Organização Pan-Americana de Saúde; 2001.

20. Reilly S, Reid J, Skeat J, Cahir P, Mei C, Bunik M; Academy of Breastfeeding Medicine. ABM clinical protocol \#18: guidelines for breastfeeding infants with cleft lip, cleft palate, or cleft lip and palate, revised 2013.Breastfeed Med. 2013; 8(4):349-53.

21. Arth AC, Tinker SC, Simeone RM, Ailes EC, Cragan JD, Grosse SD. Inpatient Hospitalization Costs Associated with Birth Defects Among Persons of All Ages - United States, 2013. MMWR Morb Mortal Wkly Rep. 2017;66(2):41-6.

22. Cucu IA, Chifiriuc MC. Congenital Heart Disease: Global Burden and Challenges to Eliminate Health Disparities. Ann Public Health Reports. 2018; 2(1): 26-9

23. Lawley CM, Lain SJ, Figtree GA, Sholler GF, Winlaw DS, Roberts CL. Mortality, rehospitalizations and costs in children undergoing a cardiac procedure in their first year of 
life in New South Wales, Australia. Int J Cardiol. 2017; 241: 156-62.

24. Ratnasiri AWG, Gordon L, Dieckmann RA, Lee HC, Parry SS, Arief VN, DeLacy IH, Laksminrusimha S, DiLibero RJ, Basford KE. Smokingduring Pregnancy and Adverse Birth and Maternal Outcomes in California, 2007 to 2016. Am J Perinatol. 2019. doi: 10.1055/s-0039-1693689.[Online ahead of print.]

25. Wehby GL, Uribe LM, Wilcox AJ, Christensen K, Romitti PA, Munger RG, Lie RT. Interaction between smoking and body mass index and risk of oral clefts. Ann Epidemiol. 2017; 27 (2): 103-7.e2

26. Li R, Lodge J, Flatley C, Kumar S. The burden of adverse obstetric and perinatal outcomes from maternal smoking in an Australian cohort. Aust N Z J Obstet Gynaecol. 2019; 59 (3): 356-61.
27. Morrow LA, Wagner BD, Ingram DA, Poindexter BB, Schibler K, Cotten CM, Dagle J, Sontag MK, Mourani PM, Abman SH. Antenatal Determinants of Bronchopulmonary Dysplasia and Late Respiratory Disease in Preterm Infants. Am J Respir Crit Care Med. 2017; 196 (3): 364-74.

28. Santos JP, Pileggi-Castro C, Camelo JS Jr, Silva AA, Duran P, Serruya SJ, Cecatti JG. Neonatal near miss: a systematic review.BMC Pregnancy Childbirth. 2015; 15:320.

29. Domingues RMSM, Figueiredo VC, Leal MdC. Prevalence of pre-gestational and gestational smoking and factors associated with smoking cessation during pregnancy, Brazil, 2011- 2012. PLoS ONE. 2019; 14 (5): e0217397.

30. López MB, Lichtenberger A, Conde K, Cremonte M. Psychometric Properties of Brief Screening Tests for Alcohol Use Disorders during Pregnancy in Argentina. Rev Bras Ginecol Obstet. 2017; 39 (7): 322-9.

Received on October 21, 2019

Final version presented on March 20, 2020

Approved on June 29, 2020 